"Hasek'Petraskova" — 2009/2/18 — 23:22 — page 289 — \#1

\title{
Teaching of financial mathematics using Maple
}

\author{
Roman HaŠEK and Vladimíra PetrášKova
}

Abstract. The paper deals with the application of computer algebra system Maple in teaching of financial mathematics. In the Czech Republic financial mathematics is included in the curricula of grammar and secondary school. Therefore, this subject is also taught at pedagogical faculties. Most concepts of financial mathematics are difficult to understand for students. In the paper we show the ways of facilitation understanding these concepts using tools of Maple. The main result is in preparing special maplets which enable interactive studying of the principles of such concepts. Each of these maplets deals with particular financial problem from real life, e.g. mortgage credit, consumer credit, credit card etc.

Key words and phrases: financial mathematics, Maple, maplets, teaching.

ZDM Subject Classification: M30, U70, N80.

\section{Introduction}

The paper deals with the application of computer algebra system Maple in teaching of financial mathematics at the Pedagogical faculty of the University of South Bohemia (hereinafter PF USB).

Financial products such as account current, building saving, private pension scheme, instalment selling, consumer or mortgage credit, form a natural part of our lives. Thus the knowledge necessary for understanding of their offer and a proper selection of a specific product undoubtedly should be included in the curricula of grammar and secondary schools. Financial tasks along with corresponding concepts have more and more been included in the textbooks. It is 


$$
\text { "Hasek'Petraskova" — 2009/2/18 — 23:22 — page } 290 \text { — \#2 }
$$

evident that the teachers also shall properly be prepared for this situation, which is the task of study subject "Financial mathematics" included in the curricula of our Pedagogical Faculty of the University of South Bohemia (hereinafter PF USB) but also in most of other faculties preparing the teachers of mathematics for grammar and secondary school. The former graduates from the faculties, where this subject was not included in their curricula yet, can complement necessary knowledge of financial mathematics in the programme of further training of pedagogues. In addition, at PF USB as at one of a few universities, there is accredited not-teaching BSc. study program "Financial mathematics" whose graduates are prepared for the work in financial sphere.

The financial practice cannot dispense with computer programs. In addition to special single-purpose programs, spreadsheets are most utilised (Microsoft Excel, OpenOffice). Our students are also carefully prepared for their operation and a proper utilisation. They acquire essential use in subject "Computation aids of financial mathematics" getting familiarised with specific applications in various special subjects. The task of our teaching is to provide the graduates with such skills and knowledge that will enable them their best possible activities in labour market. However, the field of bank (financial) services is one of the most dynamic fields. Only such person can properly react to continuous development who, in addition to the current status of the offer of bank products, also understands their theoretical basis, i.e. general concepts of financial mathematics and relations between them.

A long-term experience in teaching of financial mathematics at our faculty shows that most concepts of financial mathematics are difficult to understand for students and that sample solutions to selected tasks and modelling of discussed relations are helpful to a deeper understanding of respective concepts and relations between them. For these purposes, the authors successfully applied the program of type CAS (Computer algebra program), specifically of program Maple. There is an invaluable combination of symbolical, numerical and graphical possibilities of this program for modelling of financial relations. In addition, version 11 enables interconnection with program Microsoft Excel.

Thus, presently the utilisation of program Maple for modelling of discussed concepts and investigation of their relations is an integral part of the lectures and seminars in subject Financial mathematics both for BSc. study program and for teaching programs. During 6 years of teaching of the subject, a lot of materials were collected, mostly in the form of files of program Maple from version 5 to version 11 of the files as well as surely also experience in their utilisation,
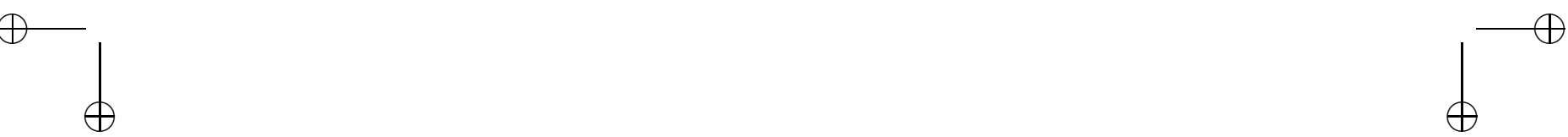
"Hasek'Petraskova" — 2009/2/18 — 23:22 — page 291 — \#3

which naturally resulted in the possibility of collecting, sorting and commenting of these materials along with their providing to the students in a suitable form. The authors decided that this will be the form of interactive (multimedia) electronic aid available at the Internet. This form corresponds with the aid content and its didactic mission enabling interpretation of theory and solutions to the tasks of financial mathematics with the application of Maple and a student is provided with the tool for his/her own experimentation. However, this is the only form to assure the possibility of continuous updating according to the current status of the market with financial products along with permanent availability to all students of financial mathematics, in a daily or combined form of study or in the program of further training of teachers.

Therefore, the authors implement project "Multimedia tool for teaching of financial mathematics" whose objective is to create corresponding multimedia aid utilising available facilities of program Maple 11 and topically reacting to changes in the conditions (e.g. changes in interest rates, the creation of new products) in the bank and financial sphere. This paper states some sub-results of this project.

\section{Financial mathematics at grammar and secondary schools in the Czech Republic}

As above stated, in the Czech Republic financial mathematics is included in the curricula of both grammar and secondary school. At grammar school, the pupils are familiarised with essential concepts of financial mathematics, simple and compound interest in the subject matter dealing with per cents by handling the tasks of the type as follows:

At the beginning of the year, $M r X Y$ deposited to AE-bank for one year the amount of $C Z K$ 10,000.00 with interest rate 1.2\%. Mr XZ deposited on the same day the same amount to AD-bank, interest rate of his deposit is $1.4 \%$. Interest charges are in both cases $15 \%$.

a) Who will have a higher amount at the end of the year; $M r X Y$ or $M r X Z$ ?

b) By how many Czech crowns?

At secondary school, the students face financial mathematics in the subject matter dealing with arithmetical and geometrical sequence. Examples for practicing of this subject matter are often quite theoretical ones. Thus, the introduction of the tasks in financial mathematics, in addition to preparation of students for 


$$
\text { "Hasek'Petraskova" — 2009/2/18 — 23:22 — page } 292 \text { — \#4 }
$$

common life situations, also brings a simple activation of teaching. This pertains to the tasks of the type as follows:

Within his student account, student $X Y$ applies the bank for study loan in the amount of CZK 300,000.00 for the period of 5 years. The credit will only be repaid after completion of the study - during the period of study, only interest in drawn credit principal will monthly be paid. After completion of study, the credit will be repaid by regular monthly annuity instalments. Let us suppose that the student is at the beginning of the $3^{\text {rd }}$ year of university, i.e. he will pay interest for 3 years and monthly annuity instalments for 2 years. Interest rate determined for this period is $9.18 \%$. What amount of interest will he pay each month for the period of 3 years and what will be the amount of his monthly instalment for the period of 2 years? Draw up curtail schedule for this period.

Another benefit of teaching of financial mathematics at grammar and secondary school is a message for the pupils that mathematics can be applied in a common life. In addition, this subject identifies mutual relations and connections between various topics of subject matter, e.g. finance, mathematics and civics (most bank products only relates to the citizens of EU countries).

\section{Financial mathematics at our university (faculty)}

With regard to the scope of teaching of financial mathematics at grammar and secondary school it is desirable that corresponding subject should be an integral part of the curricula of teaching study program.

At PF USB, subject "Financial mathematics" is taught in the following two study programs:

1) Special BSc. study program "Financial mathematics" which prepares students for working in financial branch.

2) Study program "Teaching of mathematics at grammar and secondary school"

With regard to the focus of the above two study programs it is evident that hourly grant of subject "Financial mathematics" within these programs differs. BSc. program "Financial mathematics" also includes compulsory subject "Computation aids of financial mathematics", that can be selected by students of teaching as optional one. Specific hourly grants are stated in the following Table 1. 


$$
\text { "Hasek'Petraskova" — 2009/2/18 — 23:22 — page 293 — \#5 }
$$

Table 1. Hourly grant

\begin{tabular}{|c|c|c|c|c|}
\hline \multicolumn{5}{|c|}{ Branch of Financial mathematics } \\
\hline $\begin{array}{c}\text { Name of } \\
\text { subject }\end{array}$ & $\begin{array}{c}\text { Number } \\
\text { of credits }\end{array}$ & Scope of teaching & $\begin{array}{c}\text { Recommended } \\
\text { year and term }\end{array}$ & $\begin{array}{c}\text { Way of } \\
\text { completion }\end{array}$ \\
\hline $\begin{array}{c}\text { Financial } \\
\text { mathematics }\end{array}$ & 5 & 2 lectures +1 seminar & $2 / \mathrm{W}$ & Exam \\
\hline $\begin{array}{c}\text { Computation } \\
\text { aids of financial } \\
\text { mathematics }\end{array}$ & 6 & 2 lectures +1 seminar & $3 / \mathrm{S}$ & Exam \\
\hline \multicolumn{7}{|c|}{ Branch of Teaching } & Recommended \\
\hline $\begin{array}{c}\text { Name of } \\
\text { subject }\end{array}$ & $\begin{array}{c}\text { Number } \\
\text { of credits }\end{array}$ & Scope of teaching & year and term & completion \\
\hline $\begin{array}{c}\text { Financial } \\
\text { mathematics }\end{array}$ & 5 & 2 lectures +1 seminar & $2 / \mathrm{W}$ & Exam \\
\hline
\end{tabular}

The objective of subject "Financial mathematics" is to familiarise students with general concepts and the bank and finance products such as

- simple, compound, blended and continuous interest,

- discounting,

- saving (short-term, long-term, combined), building saving,

- pensions as regular payments from investment,

- credits (consumer, mortgage), hire purchase companies, credit cards,

- account currents,

- bonds

- bills of exchange

- shares

Within subject "Computation aids of financial mathematics" that, as we know, is for the students of teaching optional one, spreadsheet Excel along with computer algebra systems Mathematica and Maple, financial on-line calculators at the Internet and public-domain software are utilised for execution of financial calculations. 


\section{Multimedia tool for teaching of financial mathematics}

As already said, in study of financial mathematics a student gets familiarised with a lot of concepts and formulae that he/she should properly apply in practice. For selection and a proper use of specific function, a thorough understanding of the issue to be settled is often necessary. According to long-term experience, the use of program CAS can significantly be helpful to this purpose, i.e. both to modelling of the relations by described functions and to sample solution of type tasks.

The objective of project "Multimedia tool for teaching of financial mathematics" is to create interactive aid of multimedia character - www page that with contribution of CAS of program Maple would be helpful to a better understanding of the curriculum of subject "Financial mathematics". The page is available to all users of the Internet at the address http://www.pf .jcu.cz/ fim. Interactive materials - the tasks describing model situations from financial practice are created by the use of the aids of program Maple 11. For processing of text documents and their presentation, program Adobe Acrobat 7 Professional is used.

Interactive aid - www page are of an open character. Selected topical problems in the field of finance and banking are solved on specific examples and model situations. In addition to interpretation and illustration of general concepts of financial mathematics, its sense and at the same time contribution is directing of students to purposeful application of information technologies in solution to common financial operations.

The basic idea of the page is evident in Figure 1. In the left part of the window we can see the content of the page. Its items comply with the basic topics of the curriculum of financial mathematics. After clicking onto some of them, e.g. Bonds, specification of the relevant sample tasks will appear in the main window panel. For each specification, the user can select from three applications Maple related to the task. Then the user calls specific application by clicking onto the relevant password as it is shown in Figure 1. Under password "Tutorial" there is a hidden so-called "smart document". This is interactive document, including a sample solution processed and commented in detail, also enables to create and settle, by a change in parameters, the whole group of similar tasks. Password "Maplet" represents special interactive application created in program Maple that is related to the task specification. The application runs in a separate window for whose opening it is not necessary to start-up program Maple. Password "Maple code" 
brings the task solution code entered in conventional line mode of the program. We will return to each application in the following example of the task solution from chapter "Bonds" commented in detail.

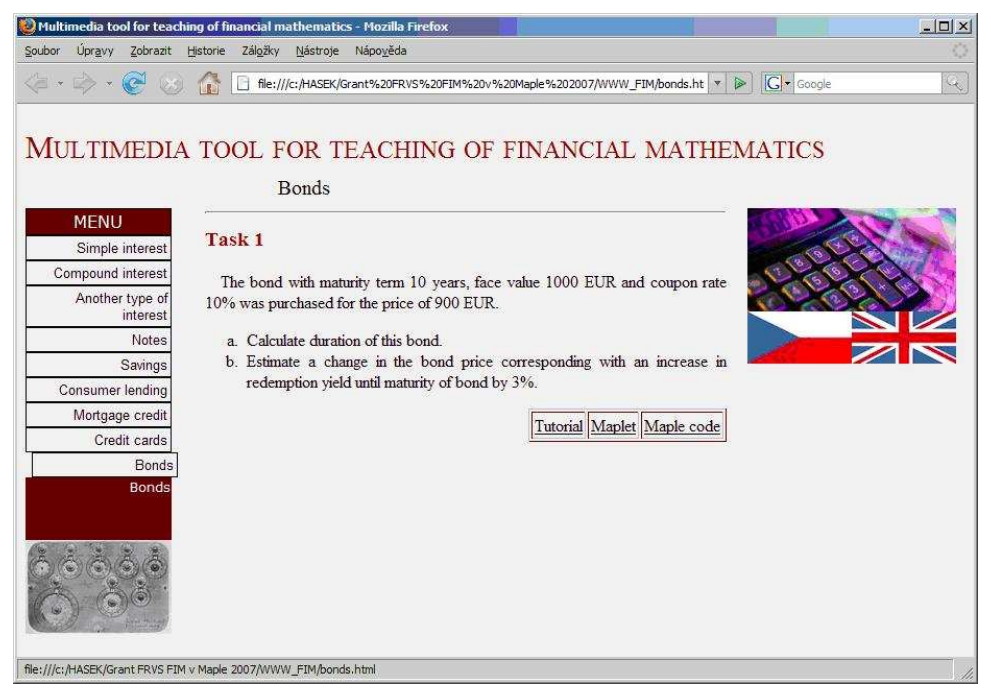

Figure 1. Example of multimedia teaching text

Let us illustrate philosophy of the page - aid on one specific example. This pertains to the following task dealing with bonds:

The bond with maturity term 10 years, face value EUR 1,000.00 and coupon rate $10 \%$ was purchased for the price of EUR 900.00 .

a) Calculate duration of this bond.

b) Estimate a change in the bond price corresponding with an increase in redemption yield until maturity of bond by $3 \%$.

A version of the task specification on www page can be seen in Figure 1. Let us select gradually each of the stated passwords "Tutorial (Maple document)", "Maplet", "Maple code".

\section{Tutorial (Maple document)}

The relevant interactive document includes derived and explained general concepts of respective issue, in this case from the field of bond market (duration, 
bond price alteration in a change in interest rate $i$ ). In addition to definition of corresponding concepts, this document clarifies the basic regularities between particular parameters (interest rate $i$, coupon rate $c$ and maturity term $n$ ). The whole document is created in environment Maple. It represents combination of the text and mathematical formulae to which we can apply symbolical, numerical and graphical program tools. Thus, the user will get a tool for solution to the whole group of related tasks differing in set points. With such a tool, the user can easily start experimenting that is the best way to understand the relevant relations.

For illustration, we state selected parts of the document dealing with the solution to respective task.

Firstly, the task specification is reminded.

\section{DURATION AND BOND PRICE}

EXAMPLE: The bond with maturity term 10 years, face value CZK $1,000.00$ and coupon rate $10 \%$ was purchased for the price of CZK 900.00 .

a) Calculate duration of this bond (the duration expresses time in which our invested capital will return /taking into account time value of money/).

b) Estimate a change in the bond price corresponding with an increase in redemption yield until maturity of bond by $3 \%$.

Commentary, possibly derivation of used formulae follow.

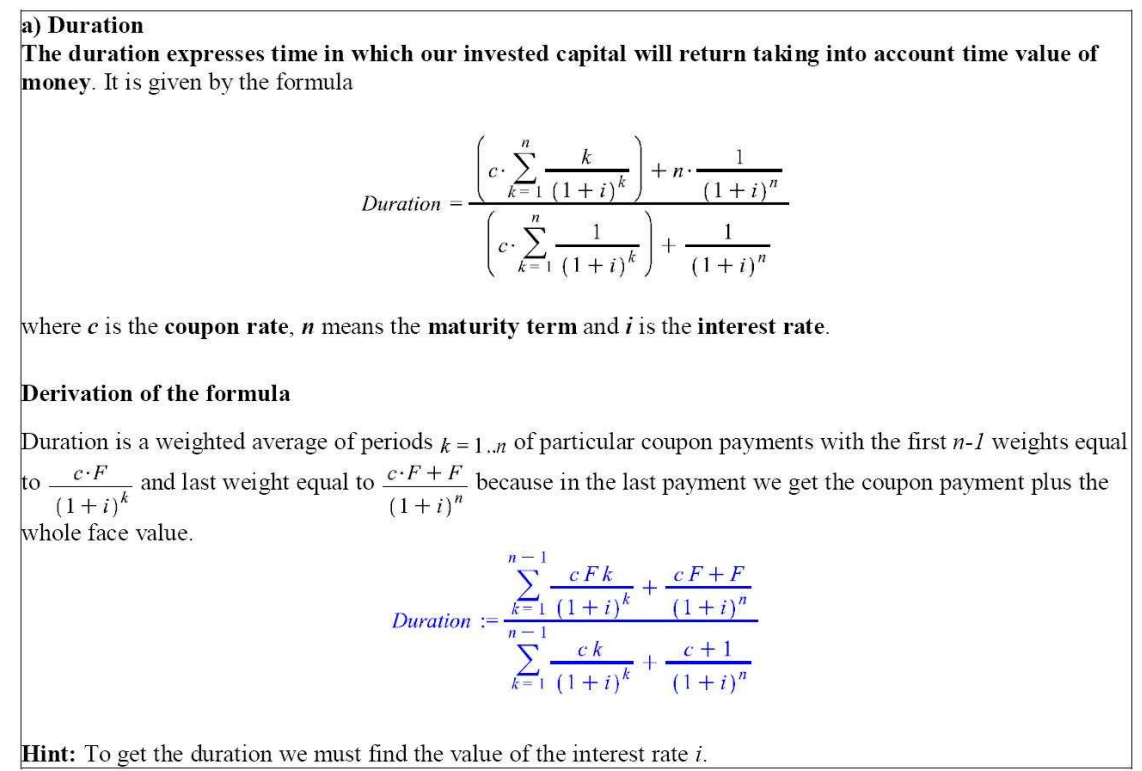


A detailed solution step by step is provided with the commentary on particular steps of the solution (left column). Then, each formula is completed with brief operating instructions (right column, the text in italics) so that the document user will only need the minimum command of work with program Maple. As already said, the document is interactive one. A change in the values of parameters $P, c$, $n, F$ in the first line and subsequent recalculation of formulae we acquire the solution corresponding with new values. We analogously proceed also with solution to task b) that is not stated here due to a brief text of this document.

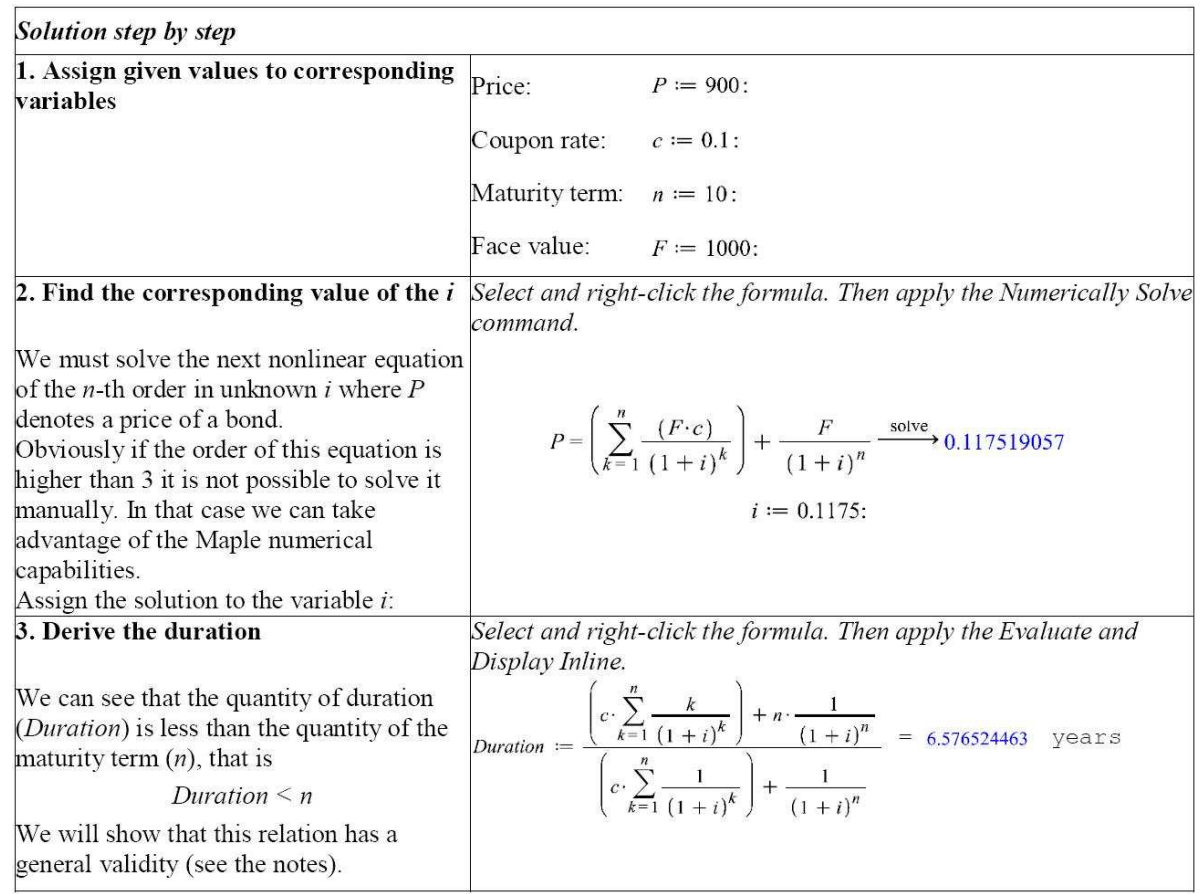

The task of the document is not a mere solution to respective task or related tasks. Its parts are also detailed commentaries on properties of considered actions. 


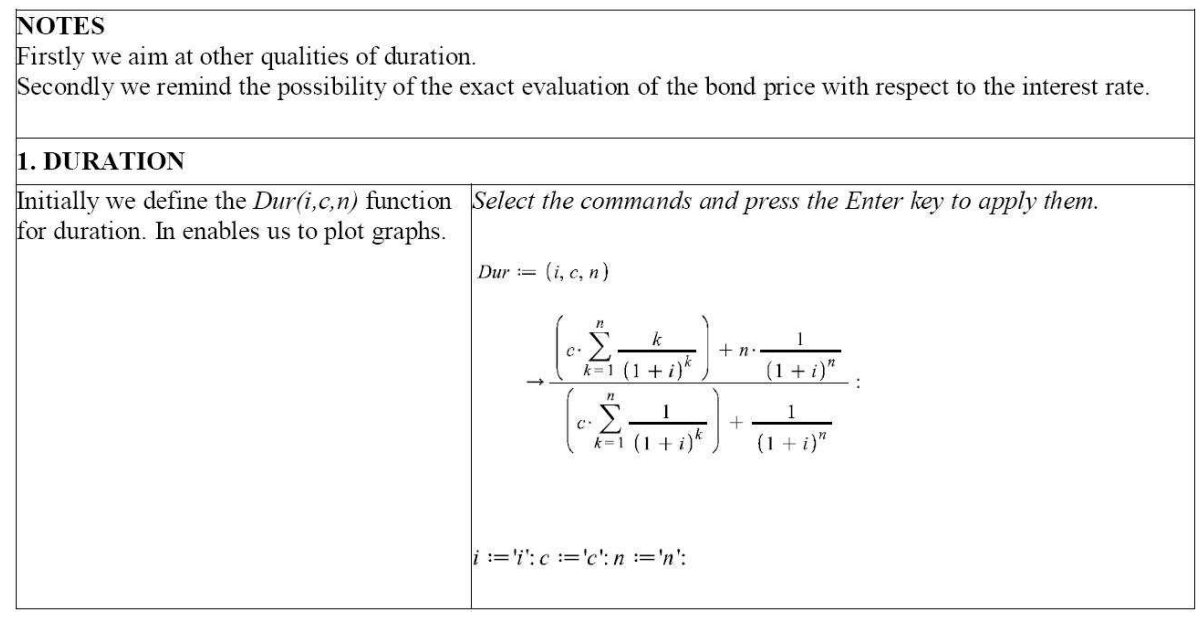

The visualisation contributes to clarification of functioning of applied relations. The visualisation utilises graphical windows in combination with scroll bars. Thus the effect of continuous changes in a selected parameter upon a monitored quantity can be monitored.

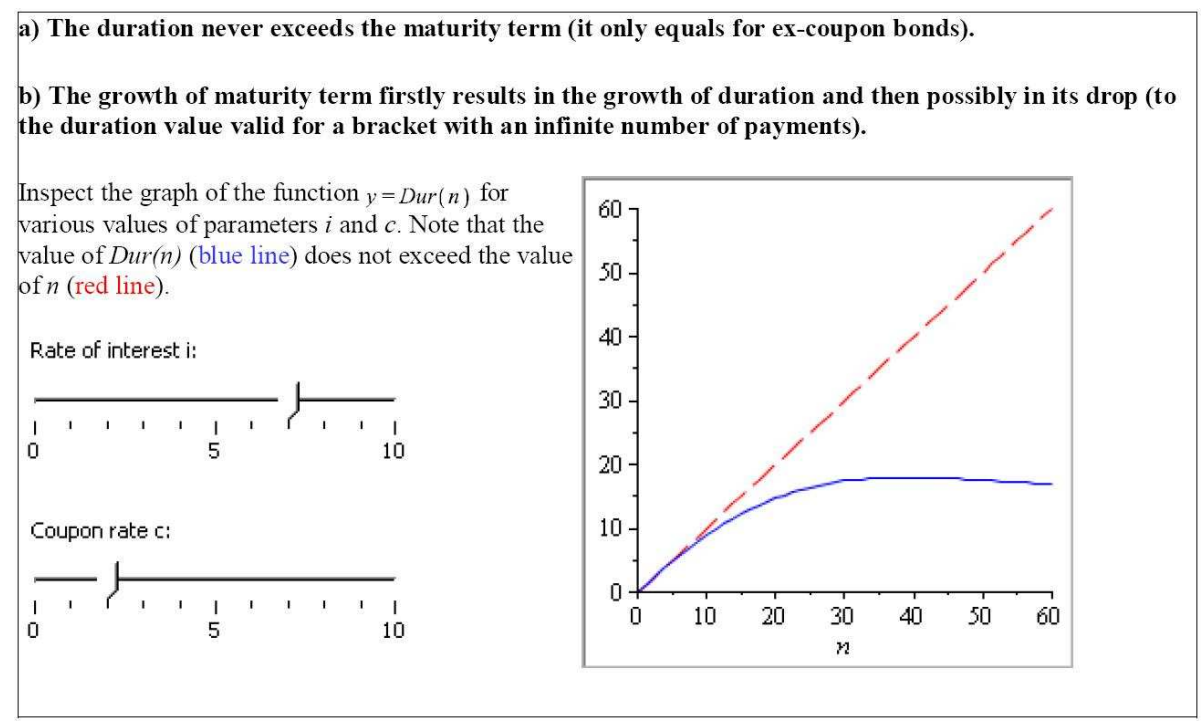


An integral part of the document is specification of the tasks for practicing a discussed topic.

\section{EXERCISES:}

Exercise 1: You know the duration (3 years), maturity term (5 years) and the interest rate (3\%) of a bond. Find its coupon rate. Exercise 2: You know the duration (3 years), maturity term (5 years) and the coupon rate (5\%) of a bond. Find its interest rate.

\section{Maplet}

Program Maple enables to create - program so-called maplets. This pertains to interactive applications running in a separate window that utilise computation possibilities of the core of program Maple. The window of maplet can be equipped with a lot of various controls, input and output text and graphic fields, help, commentaries etc. Thus the user will get a tool by means of which he/she can utilise all possibilities of program Maple without controlling this program (the reader acquires detailed information on the creation of maplets by setting command > ?roadmap;). Program Maple need not be in the utilisation of maplet even started, however unfortunately it shall be installed on respective computer. In this case (see Figure 2) by means of the above Maplet it is possible to calculate bond duration in varying value of interest rate $i$, coupon rate $c$ and maturity term $n$. Everything is accompanied by graphic pictures from which the student can become aware of various regularities (e.g. an increase in coupon rate is accompanied by a decrease in duration).

\section{Maple code}

The last selection "Maple code" offers the task solution code entered in conventional line mode of program Maple. It allows the user familiarised with syntax of program Maple a prompt insight into the task solution and it enables him/her to detect hidden links between particular task parameters by means of experimentation with specification. 
"Hasek'Petraskova" — 2009/2/18 — 23:22 — page 300 — \#12

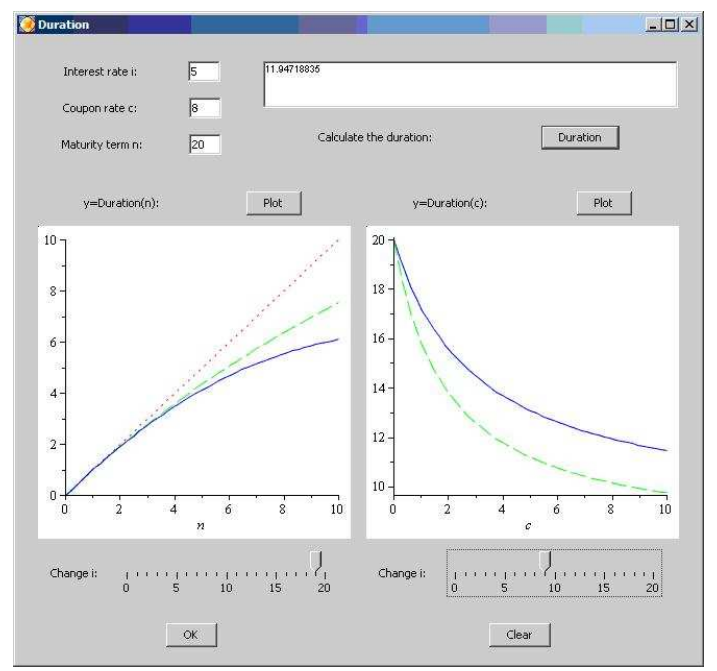

Figure 2. Maplet "Duration"

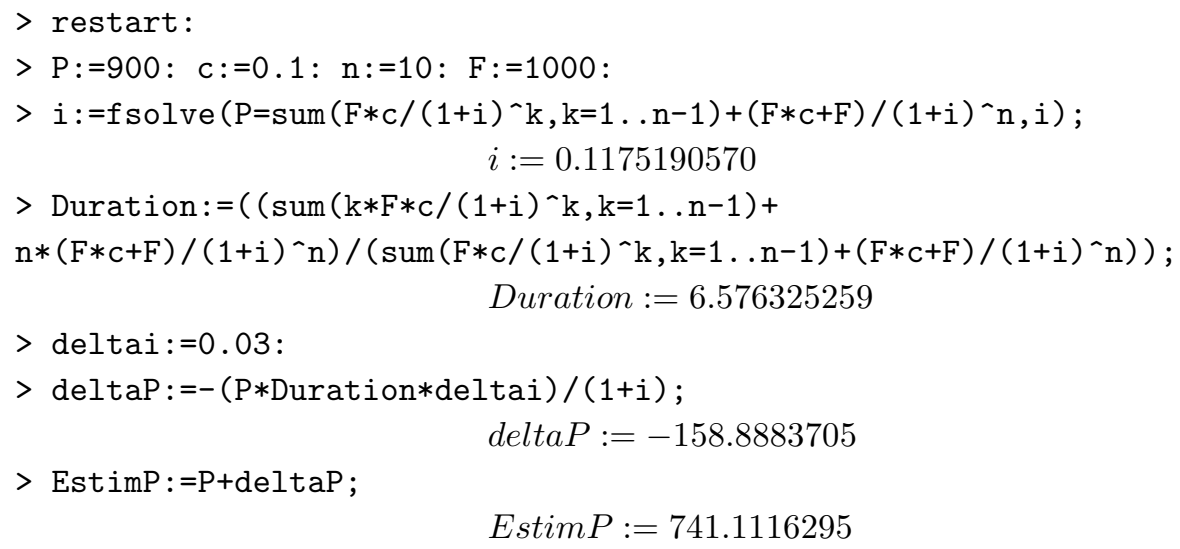

Due to the fact that the students of PF USB in České Budějovice are familiarised with program Maple both in subject Computer technology for mathematicians (compulsory subject) and in subject Solutions to problems using Derive and Maple (optional subject), they do not have any troubles concerning their work with program Maple. 


$$
\text { "Hasek'Petraskova" — 2009/2/18 — 23:22 — page 301 — \#13 }
$$

\section{Conclusion}

If we in conclusion summarise advantages and drawbacks of the use of program Maple in teaching of Financial mathematics, we can state that the advantages prevail. By the use of program Maple the students can solve the tasks based on experimentation and modelling, learning by experience, by own mistakes, by own discoveries. In addition, they can solve the tasks more demanding from numerical point of view. On the other hand, the drawback consists in the fact that in the use of maplets the students can pass to a certain algorithmization and they do not become aware of the substance of respective problem.

For the persons interested in the work with the above interactive aid we would like to remind of the fact that the page has been created just now. Therefore, neither the list of the topics nor corresponding files of the tasks to be solved are definite ones.

\section{References}

[1] T. Cipra, Praktický prưvodce finanční a pojistnou matematikou [Practical guide through financial and actuarial mathematics], Ekopress, Praha, 2005.

[2] R. B. Israel, Calculus: The Maple Way, Addison Wesley Longman Ltd., 2000.

[3] Maple 11 User Manual, Maplesoft, a division of Waterloo Maple Inc., 2007.

[4] www.maplesoft.com.

[5] www.maplesoft.cz.

[6] M. B. Monagan et al., Maple 11 Introductory Programming Guide, Maplesoft, a division of Waterloo Maple Inc., 2007.

ROMAN HAŠEK and VLADIMÍRA PETRÁŠKOVA

PEDAGOGICAL FACULTY

UNIVERSITY OF SOUTH BOHEMIA IN ČESKÉ BUDĚJOVICE

CZECH REPUBLIC

E-mail: hasek@pf.jcu.cz

E-mail: petrasek@pf.jcu.cz

(Received September, 2007) 